\title{
New closterovirus in 'Redglobe' grape causes decline of grafted plants
}

\author{
Jerry K. Uyemoto $\square$ Adib Rowhani $\square$ Donald Luvisi $\square \quad$ C. Randy Krag
}

\begin{abstract}
In California, first-generation table grape vineyards were planted on their own roots. But in recent years growers have been replanting onto acreage previously in grapes more often. Grafted plants are being sought to overcome nematodes and other site-related problems. We investigated the etiology of the decline and death of 'Redglobe' table grape scions propagated on different rootstocks, using a series of greenhouse and field experiments, and reverse transcriptasepolymerase chain reaction (RT$P C R$ ) assays. We determined that a specific graft-transmissible agent was closely associated with declining young grapevines. The 'Redglobe' closterovirus that we identified was given the trivial name Grapevine rootstock stem lesion associated virus (GRSLaV).
\end{abstract}

Tn California, first-generation table Irape vineyards have historically been planted on their own roots. However, replanting onto acreage previously in grapes is occurring more often, and grafted plants are being sought to overcome nematodes and other site-related problems. 'Redglobe' is a popular UC-patented table grape grown worldwide. When co-author Luvisi began his rootstock trials for table grapes, Redglobe was included. But he encountered a problem.

In 1992, Luvisi had planted several table-grape rootstock trials in various
Kern County vineyards, consisting of five cultivars on nine rootstocks and own-rooted scions (cultivars planted on their own roots). Each vineyard site consisted of five complete replications of scion-rootstock combinations and own-rooted scions. In four trials, the horticultural responses of the cultivar Redglobe were being evaluated. However, in 2 years all Redglobe plants on rootstocks 5BB, 5C, 3309C and 1103P had declined and died. Involvement of a graft-transmissible agent (GTA) was suspected. We initiated the present study 4 years later to determine the etiology of Redglobe grapevine decline. A preliminary report has been published (Uyemoto et al. 2000).

\section{Rootstock test plant trial}

We evaluated 'Cabernet Sauvignon' scions - bench-grafted onto nine rootstocks (Ramsey, Harmony, Freedom, 039-16, 5BB, 5C, 3309C, 101$14 \mathrm{Mtg}$ and 1103P; referred to collectively as "test plants") — as potential indicators for GTAs causing graft incompatibility. Test plants were established in the field in spring 1996 at Armstrong Tract, Department of Plant Pathology, UC Davis. Approximately 18 months later, Redglobe canes were collected from the Foundation Plant Materials Service (FPMS) at UC Davis and from a commercial nursery. Each source was chip-budded (two buds per plant) on the scion portion of the test plants. Three test plants per rootstock were graft-inoculated, and a total of 27 test plants were used per collection. The viability of inoculum bud chips was visually assessed 30 days postinoculation. Noninoculated test plants served as healthy controls.

In the first full growing season following graft inoculation, test plants were inspected for foliar symptoms. Prior to 1998 dormancy, two red-leaf test plants, one each on rootstocks 3309C and 1103P, were sacrificed. The bark was removed and the woody cylinders examined for symptoms. Near completion of the second growing season, the three remaining red-leaf test plants, several inoculated asymptomatic test plants and healthy controls were sacrificed and their stems examined.

Other grape plants. Also in 1996, we planted bench grafts of Redglobe scion directly onto 20 each of rootstocks 5BB, 5C, 3309C and 1103P and own-rooted scions, at the same test site. A year later, only the ownrooted Redglobe grapevines survived; all others had died. Because of heavy plant losses, more bench grafts of Redglobe on rootstocks 5BB, 5C, 3309C, 101-14Mtg and Freedom (referred to collectively as Redglobe plants) were made in 1997. After callusing, these were potted, reared in a greenhouse and acclimated in a lathhouse - a covered unit built with 2-inch-wide wood or metal strips to allow air and sunlight to harden off the plants - before being transplanted to the field in late August 1997. In late 1999, all surviving Redglobe plants were removed and their stems examined using reverse transcriptase-polymerase chain reac- 
tion (RT-PCR) assays.

Assays. During sum mer 1999, leaf petioles of the three red-leaf test plants, several asymptomatic test plants (all with Redglobe inoculum), and nongrafted healthy controls were assayed by RT-PCR assay. The primers were specific for grapevine viruses B, leafroll-2, Rupestris stem-pitting strains 1, 2 and 3, and a newly discovered closterovirus in Redglobe (Rowhani et al. 2000). Closterovirus is a classification used to describe virus grouping. Until this discovery the foundation source of Redglobe was known to carry only Rupestris stem-pitting virus.

\section{Narrowing it down}

In both sets of 27 test plants with Redglobe inocula, at least one bud chip survived per test plant. During 1998 , leaves with solid red coloration had developed on 12 of 24 test plants (all received inocula from both Redglobe sources) on rootstocks $5 \mathrm{BB}$, $5 \mathrm{C}, 1103 \mathrm{P}$ and $3309 \mathrm{C}$, that is, the same ones affected in the commercial trials. Test plants on five other rootstocks grafted with Redglobe were asymptomatic. During this period, the woody cylinders of red-leaf test plants on 3309C and 1103P appeared normal.

Following the second dormancy after inoculation, only three red-leaf test plants had survived and resumed spring growth, in the form of weak shoot growth bearing reddish mottled leaves. These test plants were nurtured through to October 1999, before being sacrificed and examined for stem symptoms. Another seven redleaf test plants had died during first dormancy, and two others had been sacrificed prior to first dormancy.

Based on RT-PCR assays, all three surviving red-leaf test plants (two on rootstock $3309 \mathrm{C}$ and one on $5 \mathrm{BB}$ ), and most of the asymptomatic test plants

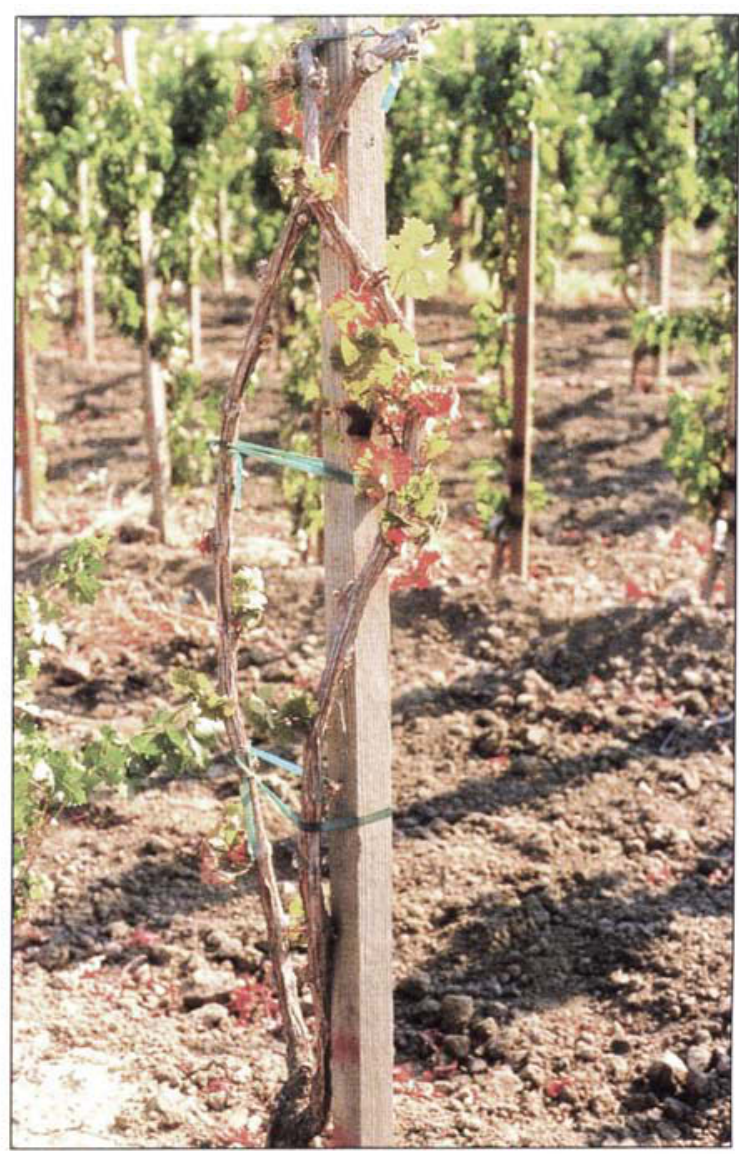

In 1992, UC scientists discovered that some Redglobe grapes planted on rootstock were declining and dying; a series of experiments was initiated to identify the cause. Test plant of Cabernet Sauvignon on rootstock 3309C with solid red coloration in late 1998, about a year after graftinoculations with source Redglobe.

grafted with source Redglobe, tested positive for the Redglobe

closterovirus. Also, a few of the grafted, but not control, test plants reacted with primers for Rupestris stempitting virus. Some inconsistencies in detecting Rupestris stem-pitting virus may be due to its uneven distribution in the inoculum source (hence the virus was not transmitted) (Rowhani, unpublished), or it was of low concentration in the test plants. All test plants (red-leaf, asymptomatic ones and healthy controls) tested negative for grapevine viruses B and leafroll-2.

The latter viruses were targeted because both, either singly or in concert, were reported to cause or to be implicated in graft incompatibility (Golino et al. 2000; Greif et al. 1995). Also, Monis and Bestwick (1997) found an association of a closterovirus with a 24 $\mathrm{kDA}$ protein (suggestive of a leafroll-
A surviving red-leaf test plant in spring 1999, now with reddish mottled leaves and weak vegetative growth. Test plant is Cabernet Sauvignon on rootstock 5BB infected with source Redglobe.

2-like GTA) and graft-incompatibility symptoms on rootstocks 5C, 3309C, SO4 and Riparia Glorie.

\section{Rootstock wood symptoms}

On red-leaf test plants, the removal of bark tissues exposed distinct lesions in the woody cylinders of specific rootstocks; these were designated grapevine rootstock stem lesions (GRSLs) (Uyemoto et al. 2000). Similar wood markings were absent on asymptomatic and control test plants.

The severity of GRSLs (in terms of length and area affected) varied widely and apparently depended on the sensitivity of the rootstock. Source rootstock $3309 \mathrm{C}$ and discrete smaller lesions on rootstock $5 \mathrm{BB}$. When viewed in cross-section, the lesions appeared to have developed during the second full growing season (1999) afRedglobe induced extended lesions on 


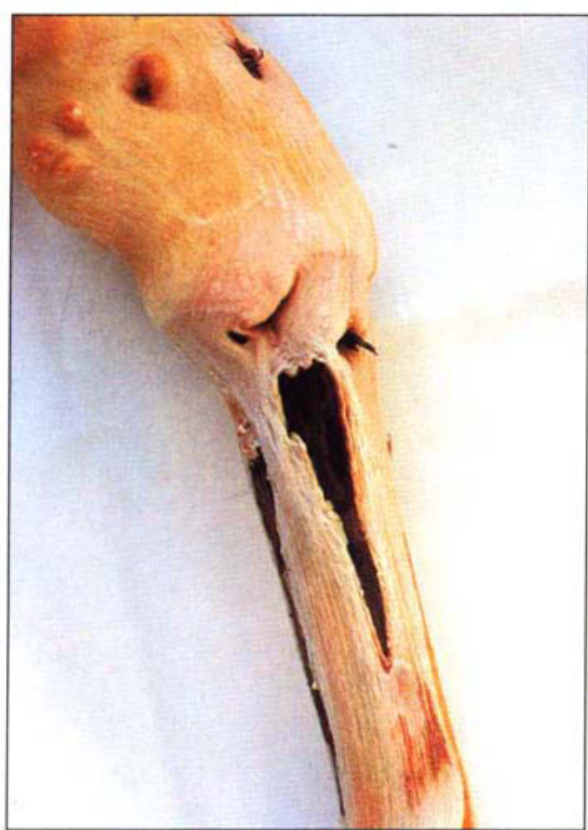

Extended grapevine rootstock stem lesions on rootstock $3309 \mathrm{C}$ of a test plant with source Redglobe that developed after a 2-year incubation. Similar markings on rootstock 3309C and source Redglobe were absent on a test plant 1 year after inoculation.

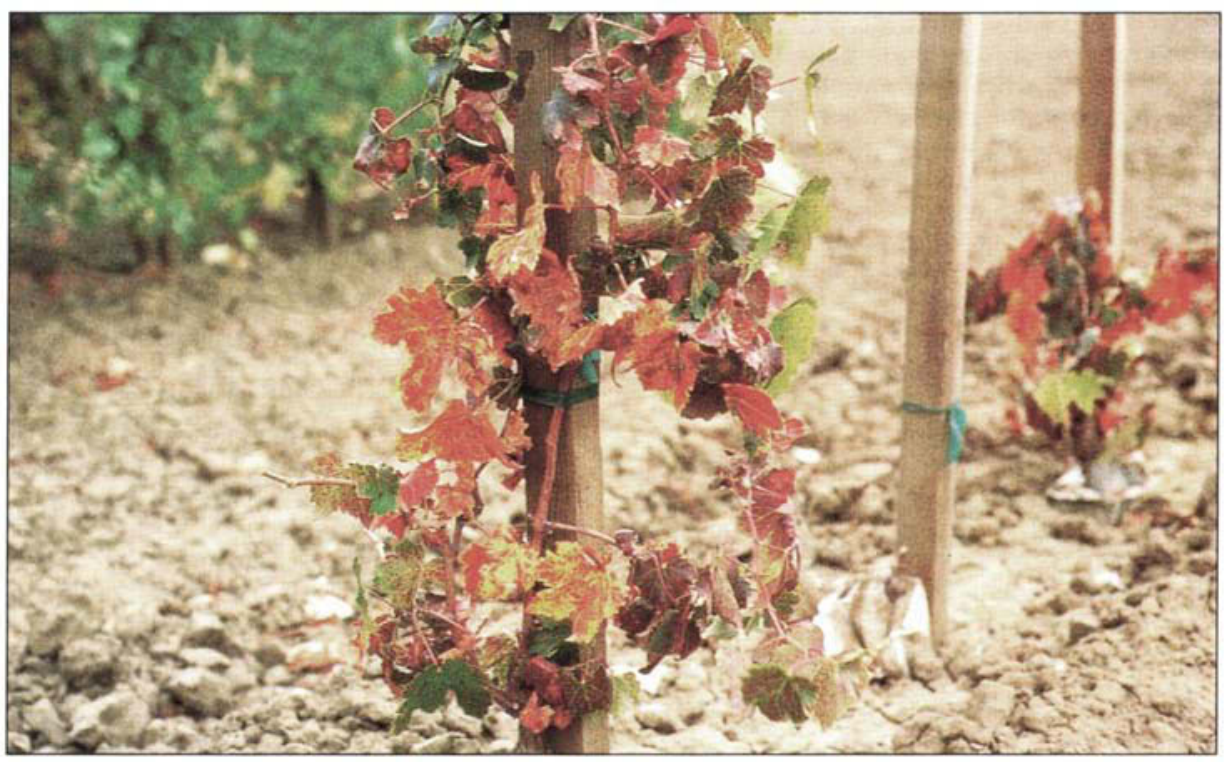

Surviving plants of Redglobe grape grow directly on rootstock 3309C, photographed 2 years after transplanting. ter infection; that is, they formed on top of the 1998 growth. Formation, or the potential for formation, of stem lesions was not found in red-leaf test plants on $3309 \mathrm{C}$ or $1103 \mathrm{P}$, sacrificed after a 1-year incubation. These results suggest that the development of GRSLs required more than a year and are similar to previous experiences

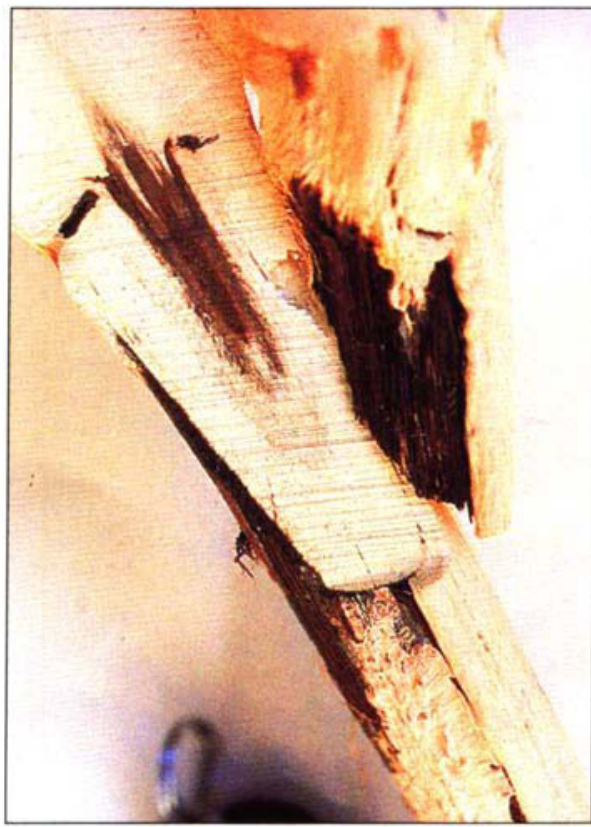

Cross-section of a large stem lesion on rootstock 3309C with inoculum from source Redglobe. Note the thin line of necrotic tissue, formed on top of the last year's growth, extending down the left edge of the rootstock. failing on rootstocks 5BB, 5C, 3309C and even Freedom. In contrast, nearly all Redglobe plants on rootstock 101$14 \mathrm{Mtg}$ and own-rooted ones survived the same growing regime. In August, all live plants were moved to the field, where several more on rootstocks 5BB, $5 \mathrm{C}$ and $3309 \mathrm{C}$ perished. The ensuing vegetative growth was weak, with reddish leaves on the affected Redglobe plants. In contrast, all Redglobe plants on rootstocks Freedom (all transplants survived once established in the field) and $101-14 \mathrm{Mtg}$, as well as own-rooted ones, were asymptomatic.

In October 1999, all surviving Redglobe plants (excluding the ownrooted ones) were examined for stem symptoms. The scion/rootstock junctions of Redglobe scions were enlarged and showed necrotic, irregular fissures in the scion overgrowths on rootstocks 5BB and 3309C. These symptoms were absent on rootstocks Freedom and 101-14Mtg. Also, severe necrosis had extended down the entire length on both $3309 \mathrm{C}$ rootstocks.

\section{Solving the mystery}

Based on these results, the decline and death of young grapevines were associated with GTA-inducing red-leaf symptoms initially and reddish mottled leaves in chronic infections. The putative GTA was identified as a new closterovirus in source Redglobe (Rowhani et al. 2000), which affected rootstocks 5BB, 5C, 1103P and 3309C; several test plants died during dormancy.

Among the surviving red-leaf test plants, GRSLs were induced on rootstocks 3309C and 5BB inoculated with source Redglobe. Furthermore, graft-incompatibility symptoms developed on Redglobe plants on the same rootstocks, suggesting some commonality in rootstock responses to the Redglobe closterovirus and decline and death of young grafted plants.

A partial sequence of the Redglobe closterovirus showed $74 \%$ similarity to GLRaV-2 (Rowhani et al. 2000). However, unlike the typical GLRaV-2 strain, the Redglobe closterovirus was latent on the standard leafroll disease indicator 'Cabernet franc' (Rowhani, 
unpublished), and on our Cabernet Sauvignon test plants growing on five rootstocks. Specific primers for the Redglobe closterovirus were designed and used for rapid detection of the virus by RT-PCR assays. It is noteworthy that the Redglobe closterovirus was recently detected by RT-PCR assays in four of 22 samples collected from poorly performing wine grapevines in commercial vineyards in Napa Valley, San Luis Obispo and Gilroy. Based on the symptoms induced in sensitive rootstocks, the Redglobe virus was given the trivial name Grapevine rootstock stem lesion associated virus (GRSLaV).

\section{Grapevine incompatibility}

Incompatibility in grapevines has been encountered throughout the world. In Australia, May (1994) discussed various aspects of graft incompatibility and cited specific examples. He concluded that "incompatibility is probably not genetically based but is due to the use of infected grafting material, be it virus, viroid or perhaps even Agrobacterium vitis." We concur. And, based on the premise that all Vitis species are genetically compatible, we set out to prove the existence of a viral entity in Redglobe and succeeded. Moreover, it can be assumed that the discovery of Redglobe closterovirus is merely the tip of the iceberg, and that similar discoveries of other graftincompatible GTAs will be made.

A new GRSL-closterovirus was identified in a certified Redglobe grapevine maintained in the FPMS foundation vineyard. The eligibility of Redglobe and other grape cultivars and clones in the California Department of Food and AgricultureGrapevine Registration and Certification Program (CDFA-R\&C) under foundation status, requires that each source pass a 2-year index on specific grape virus indicators and/or laboratory-based assays, such as ELISA (enzyme-linked immunosorbent assay). To qualify for "foundation status," each scion or rootstock source must test negative for harmful viruses and viruslike diseases when

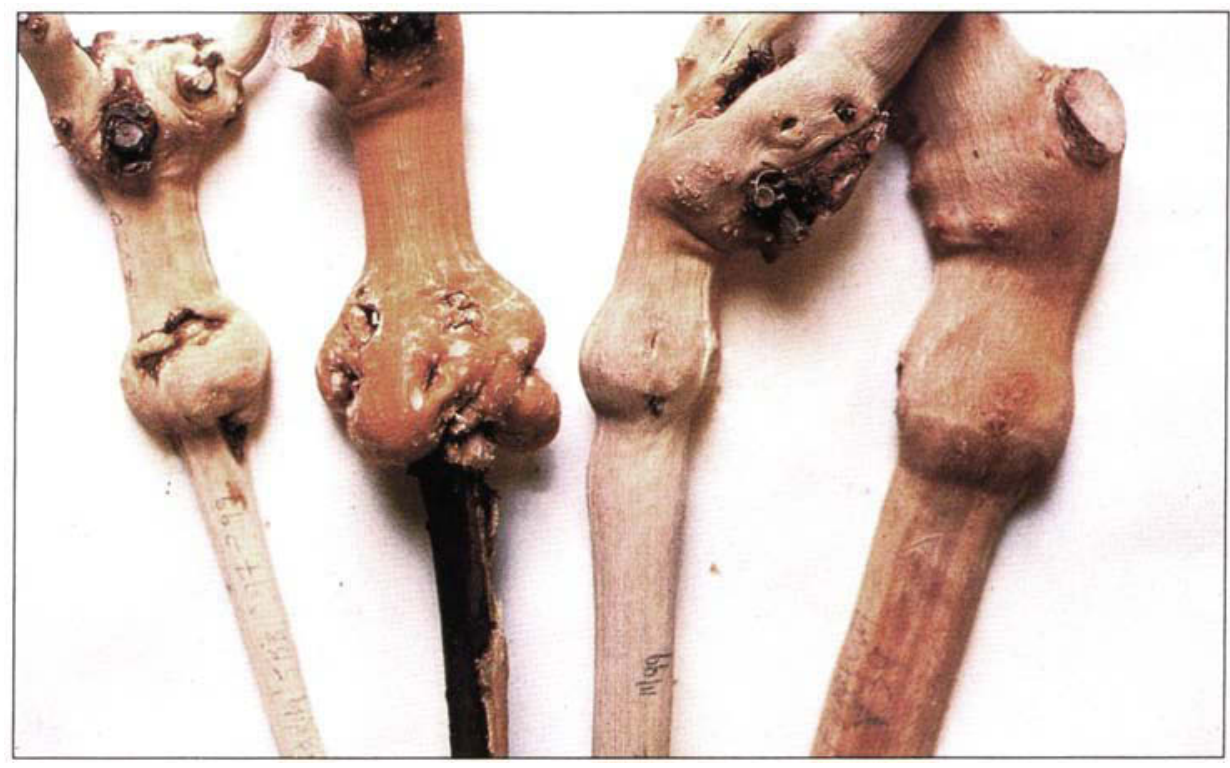

Four specimens of bench-grafted Redglobe plants show enlarged unions and necrotic fissures on the Redglobe closterovirus-sensitive rootstocks 5BB, far left, and 3309C, second from left. Rootstock 3309C also developed extensive stem necrosis. The others show normal unions and stems on tolerant rootstocks Freedom, second from right, and 101-14Mtg, far right.

indexed onto a prescribed set of biological indicators and laboratorybased assays using pathogen specific reagents. Once established in a foundation block, each plant is visually inspected twice each growing season and subjected to additional inspections and tests if a virus infection is suspected.

With the exception of Rupestris stempitting virus, the Redglobe clone had tested negative twice on the standard woody indicators and/or to grapevine virus reagents (antisera and molecular primers) for several viruses and viruslike diseases of importance (Rowhani, unpublished). In contrast, the Redglobe closterovirus was readily detected in rootstocks 5BB, 5C, 3309C and 1103P. Our results suggest that one or more of these rootstocks will be needed to qualify grapevines for the CDFA-R\&C program in the future.

J.K. Uyemoto is Research Plant Pathologist, U.S. Department of Agriculture, stationed in Department of Plant Pathology, UC Davis; A. Rowhani is Specialist, Department of Plant Pathology, UC Davis; D. Luvisi is retired Farm Advisor, UC Cooperative Extension, Kern County; and C.R. Krag is pest control advisor in private practice. The authors gratefully acknowledge the technical assistance of Cesilio Mercado in the field and Cristine Rosa for RT-PCR assays. Our appreciation is extended to Sunridge Nursery for their cooperation and gift of test plants.

\section{References}

Golino D, Sim S, Rowhani A. 2000. Identification of the latent viruses associated with young vine decline in California. In: Pro ceedings of the 13th International Council for the Study of Viruses and Virus-like Diseases of the Grapevine. Adelaide, Australia p 85-6.

Greif C, Garau R, Boscia D, et al. 1995. The relationship of grapevine leafroll-associated closterovirus 2 with a graft incompatible condition of grapevines. Phytopathologia Mediterranea 34:167-73.

May P. 1994. Using Grapevine Rootstocks: The Australian Perspective. Cowandilla, Australia: Winetitles. $62 \mathrm{p}$.

Monis J, Bestwick RK. 1997. Serological detection of grapevine-associated closteroviruses in infected grapevine cultivars. Plant Disease 81:802-8.

Rowhani A, Zhang Y-P, Golino DA, Uyemoto JK. 2000. Isolation and partial characterization of two new viruses from grapevine. In: Proceedings of the 13th International Council for the Study of Viruses and Viruslike Diseases of the Grapevine. Adelaide, Australia. $\mathrm{p} 82$.

Uyemoto JK, Rowhani A, Luvisi D. 2000. An association of rootstock stem lesions in Vitis species and different graft-transmissible agents. In: Proceedings of the 13th ICVG Meetings. Adelaide, Australia. p 83-4.

Zhang Y-P, Uyemoto JK, Kirkpatrick BC. 1998. Analysis of double-stranded RNAs from cherry trees with stem-pitting in California. Plant Disease 82:871-4. 